\title{
Differential expression of GHRH receptor and its splice variant 1 in human normal and malignant mucosa of the oesophagus and colon
}

\author{
FLORIAN HOHLA $^{1 *}$, ANGELIKA MODER ${ }^{2 *}$, URSULA MAYRHAUSER ${ }^{3}$, CORNELIA HAUSER-KRONBERGER $^{3}$, \\ ANDREW V. SCHALLY ${ }^{4}$, JOZSEF L. VARGA ${ }^{4}$, MARTA ZARANDI ${ }^{4}$, STEFAN BUCHHOLZ $^{5}$, \\ RUDOLF HUBER $^{1}$, ELMAR AIGNER ${ }^{1}$, MARKUS RITTER ${ }^{2}$ and CHRISTIAN DATZ ${ }^{1}$
}

\begin{abstract}
${ }^{1}$ Department of Internal Medicine, General Hospital Oberndorf, Teaching Hospital of the Paracelsus Private Medical University of Salzburg, Paracelsusstrasse 37, 5110 Oberndorf; ${ }^{2}$ Department of Physiology and Pathophysiology, the Paracelsus Private Medical University of Salzburg, Müllner Hauptstrasse 48, Salzburg; ${ }^{3}$ Department of Pathology, the Paracelsus Private Medical University of Salzburg, Strubergasse 21, 5020 Salzburg, Austria; ${ }^{4}$ Veterans Affairs Medical Center and South Florida VA Foundation for Research and Education, Miami, and Department of Pathology and Division of Hematology and Oncology, Department of Medicine, the Miller School of Medicine University of Miami, 1201 NW 16th Street, Miami, 33125 Florida, USA; ${ }^{5}$ Department of Gynecology and Obstetrics, University of Regensburg, Landshuterstrasse 65, 93051 Regensburg, Germany
\end{abstract}

Received March 17, 2008; Accepted April 18, 2008

\begin{abstract}
Recent evidence indicates that growth hormonereleasing hormone (GHRH) functions as a growth factor for gastrointestinal (GI) tumours. The tumourigenic effects of GHRH appear to be mediated by the splice variant 1 (SV-1) of GHRH receptor as well as the full length pituitary type receptor for GHRH (GHRH-R). We examined the protein and mRNA expression of GHRH-R and SV-1 in normal human tissues and tumours of the gastrointestinal (GI-) tract by immunohistochemical staining and reverse transcriptase (RT)-PCR. Squamous cells and squamous cell carcinoma of the oesophagus were negative for GHRH-R and SV-1, while Barrett's mucosa and adenocarcinomas of the oesophagus showed a strong expression of both receptors. The expression of GHRH-R was absent in normal colonic mucosa other
\end{abstract}

Correspondence to: Dr Christian Datz, Department of Internal Medicine, General Hospital Oberndorf, Teaching Hospital of the Paracelsus Private Medical University of Salzburg, Paracelsusstrasse 37, 5110, Austria

E-mail: c.datz@kh-obdf.salzburg.at

\section{${ }^{*}$ Contributed equally}

Abbreviations: GHRH, growth hormone releasing hormone; GHRH-R, GHRH-receptor; SV, splice variant of GHRH-R; GI-tract, gastrointestinal tract; LE, lining epithelium; NE, neuroendocrine cells

Key words: adenoma-carcinoma sequence, colon cancer, Barrett's oesophagus than neuroendocrine cells (NE) and lining epithelium (LE) but strong in tubular adenomas of the colon, while the staining for SV-1 was absent in cells other than NE. However, the expression of both receptors was significantly increased in tubulovillous adenomas and colorectal cancers. No differences were seen in protein levels for both receptors between normal and neoplastic tissues of the stomach, pancreas and liver. Because of low mRNA levels for both receptors in all samples tested, only a qualitative assessment could be made. However, mRNA for GHRH-R and SV-1 showed a nearperfect correlation with the assessment of receptor proteins by immunostaining. Our study shows that in contrast to normal mucosa, transformed mucosa of the oesophagus and the colon expresses GHRH-R and SV-1. This aberrant expression of GHRH-R and SV-1 in oesophageal and colorectal malignancies may provide a molecular target for a therapeutic approach based on GHRH antagonists.

\section{Introduction}

Many types of tumour cells are considered to be under the control of specific growth factors and neuropeptides that act by endocrine or autocrine/paracrine mechanisms to stimulate tumour proliferation and decrease apoptosis (1). Growth hormone-releasing hormone (GHRH), released by the hypothalamus, regulates the secretion of growth hormone $(\mathrm{GH})$ by binding to specific receptors for GHRH (GHRH-R) in the pituitary gland (1). Recent studies also indicate that in addition to this neuroendocrine action, GHRH functions as an autocrine/paracrine growth factor in various cancers including the neoplasms of the gastrointestinal tract $(1,2)$. This concept is supported by the demonstration by our group of the presence of GHRH-R and truncated splice variants of 
GHRH-R (SV-1-4) in non-malignant human tissues, various human cancer cell lines and human prostate cancer specimens (3-6). Of the four truncated receptors, SV-1 has the greatest structural similarity to GHRH-R and is probably the main receptor that mediates the effects of GHRH and its antagonists in tumours (7-9). In the present study, we investigated the expression of GHRH-R, SV-1, SV-2 and SV-4 in normal and malignant human tissues of the gastrointestinal tract by means of immunohistochemistry and mRNA analyses.

\section{Materials and methods}

Patients, tumours and tissue preparation. Forty normal and 46 neoplastic tissues of the GI-tract obtained from the archives of the Department of Pathology, St. Johann Hospital Salzburg, between 2004 and 2006 were included in the study. All tissue specimens were either fixed in formalin and embedded in paraffin for further immunohistochemical analysis or stored in RNA LATER ${ }^{\circledR}$ (Ambion, Austin, USA) for subsequent RNA extraction. Written informed consent was obtained from all the patients and the study was performed according to the ethical standards as set forth by Helsinki Declaration of 1983. The following normal and neoplastic specimens were subjected to analysis: normal oesophagus (3), Barrett's oesophagus (3), adenocarcinoma of the oesophagus (3), squamous cell carcinoma of the oesophagus (3), normal gastric mucosa (4), adenocarcinoma of the stomach (5), normal mucosa of the cecum (8), the transverse colon (8), the sigmoid colon (8), and the rectum (3), tubular adenoma (4), tubulovillous adenoma (3), adenocarcinoma of the colon (9), liver metastases of colonic cancers (3), normal pancreatic tissue (3), pancreatic cancer (4), insulinoma (2), gastrinoma (2), gastrointestinal stromal tumour (GIST) (2), normal liver (3) and hepatocellular carcinoma of the liver (3).

Immunohistochemistry. Immunohistochemical staining for GHRH-R and SV-1 was performed on serial sections from routine formalin-fixed paraffin embedded tissue, using EnVision+ Dual Link System (Dako, Glostrup, Denmark) for detection. Archival formalin-fixed paraffin-embedded sections $(2 \mu \mathrm{m})$ thick were deparaffinised with xylene and alcohol, followed by heat induced epitope retrieval (HIER) in Target Retrieval Solution pH 9.0 (Dako) for 40 min. Endogenous peroxidase blocking was carried out for $10 \mathrm{~min}$ with Peroxidase Blocking Reagent (Dako). The immunohistochemical detection of GHRH-R and SV1 was performed with the rabbit anti-GHRHR and anti-SV-1 polyclonal antibodies JH2321/5 and JH2317/5, respectively developed in our laboratory (10). Primary antibodies were incubated for $30 \mathrm{~min}$ at room temperature and after several washes, the detection was performed using EnVision+ Dual Link System Peroxidase (Dako), and followed by the development with diaminobenzidine (DAB). The slides were counterstained with hematoxylin. Since little experience exists in the use of these antibodies to evaluate the expression of GHRH-R and SV-1 in human tissues, in preliminary experiments, the specificity of each antibody was evaluated by pre-incubating the antiserum with increasing concentrations of the corresponding original peptide used for the immunization of rabbits, as described previously (10). These experiments showed that the immunopositivity was abolished by this treatment, which argues in favour of the specificity of our results. Negative controls, in which the primary antibody has been omitted, have also been included in the analysis (data not shown). Pituitary tissue was used as the positive control for $\mathrm{JH} 2321 / 5$ antiserum.

Double-immunofluorescence staining of NE was performed in combination with a monoclonal antibody against chromogranin A (CgA, final dilution 1/600; Dako). After heat induced pretreatment for $40 \mathrm{~min}$ in the $\mathrm{pH} 9.0$ buffer in a waterbath, primary antibodies were simultaneously incubated overnight at $4^{\circ} \mathrm{C}$. Secondary antibodies and reagents were applied consecutively for $30 \mathrm{~min}$ at room temperature (biotinylated sheep anti-mouse, Amersham, UK; Alexa Fluor 555 goat anti-rabbit IgG, Streptavidin Alexa Fluor 488 conjugate, Molecular Probes, USA).

Assessement of labelling. Semiquantitative scoring was defined by the product of the number of specifically stained tumour cells $(0$, negative; $1,1-25 \% ; 2,26-50 \% ; 3,51-75 \%$; $4,76-100 \%)$ and the intensity of staining $(0$, negative; 1 , weak; 2 , moderate; 3 , strong positivity). The product was then graded as 0 , negative; $1-4$, weak; 5-8, moderate and 9-12, strong staining. The interpretation was performed independently by two of the co-authors (C.H-K. and F.H.) each blinded to one another.

RNA isolation and reverse transcription. Total RNA extraction of tumour and pituitary was performed by a guanidiniumisothiocyanate-phenol-chloroform based procedure as described (11). Briefly, tissue specimens, previously stored in RNA LATER $^{\circledR}$ reagent (Ambion) at $-20^{\circ} \mathrm{C}$ were thawed, transferred into $500 \mu 1$ lysis/extraction buffer $(38 \%(\mathrm{v} / \mathrm{v})$ phenol, $11.8 \%$ $(\mathrm{w} / \mathrm{v})$ guanidinium-thiocyanate, $7.6 \%(\mathrm{w} / \mathrm{v})$ ammoniumthiocyanate, $3.34 \%(\mathrm{v} / \mathrm{v}) 3 \mathrm{M}$ sodium acetate $\mathrm{pH} 5.0$ and $5.74 \%(\mathrm{v} / \mathrm{v})$ Glycerol in DEPC treated $\mathrm{H}_{2} \mathrm{O}$ and disintegrated with an ultraturrax tissue homogenizer. After extraction and precipitation, total RNA was dissolved in RNase free water (Fermentas, Ontario, Canada) and stored at $-80^{\circ} \mathrm{C}$. Between 2 and $5 \mu \mathrm{g}$ total RNA was reverse transcribed using RevertAid H Minus M-MuLV Reverse Transcriptase cDNA kit (Fermentas) with random hexamer primers according to the manufacturer's instruction.

Reverse-transcriptase (RT-) PCR. RT-PCR was performed as described previously with slight modifications (5). PCR mix used for amplification of GHRH-R, SV-1, SV-2 and SV-4 consisted of $1 \mathrm{X}$ iTaq buffer (Biorad, Hercules, CA), $4 \mathrm{mM}$ $\mathrm{MgCl}_{2}, 0.25 \mathrm{mM}$ dNTPs (each), $0.2 \mu \mathrm{M}$ primers and $0.25 \mathrm{U}$ iTaq Polymerase (Biorad). Normal human pituitary was used as positive control, and GAPDH (5'-GTGAAGGTC GGAGTCAACG, 3'-TGAGGTCAATGAAGGGGTC) was used as a housekeeping gene. Human pituitary tissue served as a positive control for establishing the conditions of PCR. Negative samples were run for each RT-PCR consisting of no RNA in the reverse transcriptase reaction and no cDNA in the PCR. PCR fragments were separated on a $2 \%$ agaroseTBE gel. Tissues which did not show the corresponding bands for GHRH-R, SV-1, SV-2 and SV-4 were regarded negative for these receptors. 


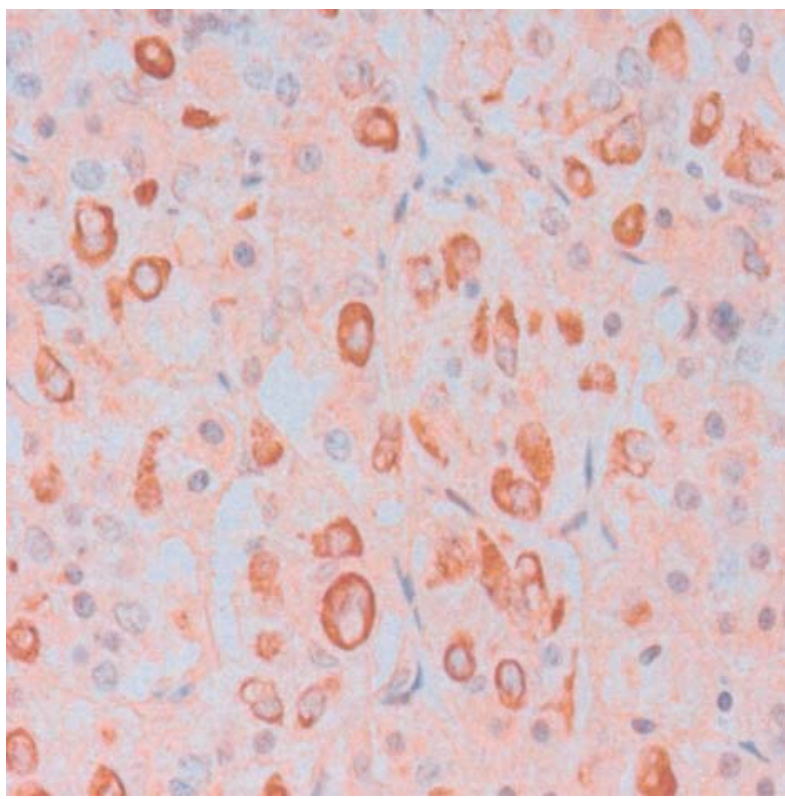

Figure 1. Immunohistochemical staining by GHRH-R antiserum JH2321/5 of normal human pituitary gland (positive control).

\section{Results}

Immunohistochemical detection of GHRH-R and $S V-1$ receptor in normal and neoplastic tissues of the GI-tract. Forty normal and 46 neoplastic tissues of the GI-tract were assessed for GHRH-R and SV-1 immunoreactivity by using the polyclonal antibodies $\mathrm{JH} 2321 / 5$ and $\mathrm{JH} 2317 / 5$ against the respective receptors, which were described previously (10). The antiserum SH2317/5 can also detect SV-2 and SV-4 (10). The specificity of the antiserum JH2321/5 against GHRH-R was shown by intense staining of GHRH-R expressing cells in human pituitary gland (Fig. 1). The staining of both types of receptors was highly specific and no adjacent tissues were stained. Squamous epithelial cells and squamous cell carcinoma of the oesophagus were negative for both receptors. On the other hand, Barrett lesions of the oesophagus and adenocarcinomas of the oesophagus were highly positive for both GHRH-R and SV receptors (Fig. 2a and b). Normal gastric mucosa as well as gastric cancers (adenocarcinomas) showed a strong expression of GHRH-R, but lacked SV receptors immunoreactivity. As shown in Fig. 2c, only NE and LE of normal colonic mucosa exhibited weak immunohistochemical staining for GHRH-R, while crypts remained unstained. Neuroendocrine origin of colonic mucosa cells was demonstrated by double staining with anti-GHRH-R antibody JH2321/5 and chromogranin A (Fig. 2e and g). GHRH-R receptors were found to be strongly positive in tubular adenomas (Fig. 2i), tubulovillous adenomas (Fig. 2k) and adenocarcinomas of the colon (Fig. 2m). The staining for SV receptors was only positive in NE while the epithelium of normal colonic mucosa (Fig. 2d) and mucosa of tubular adenomas (Fig. $2 \mathrm{j}$ ) did not show SV receptor immunoreactivity. Double staining of NE in normal colon mucosa with anti SV-1 antibody $\mathrm{JH} 2317 / 5$ and chromogranin $\mathrm{A}$ is shown in Fig. $2 \mathrm{f}$ and $\mathrm{h}$. SV receptors were strongly detected in tubulovillous adenomas (Fig. 21) and adeno-

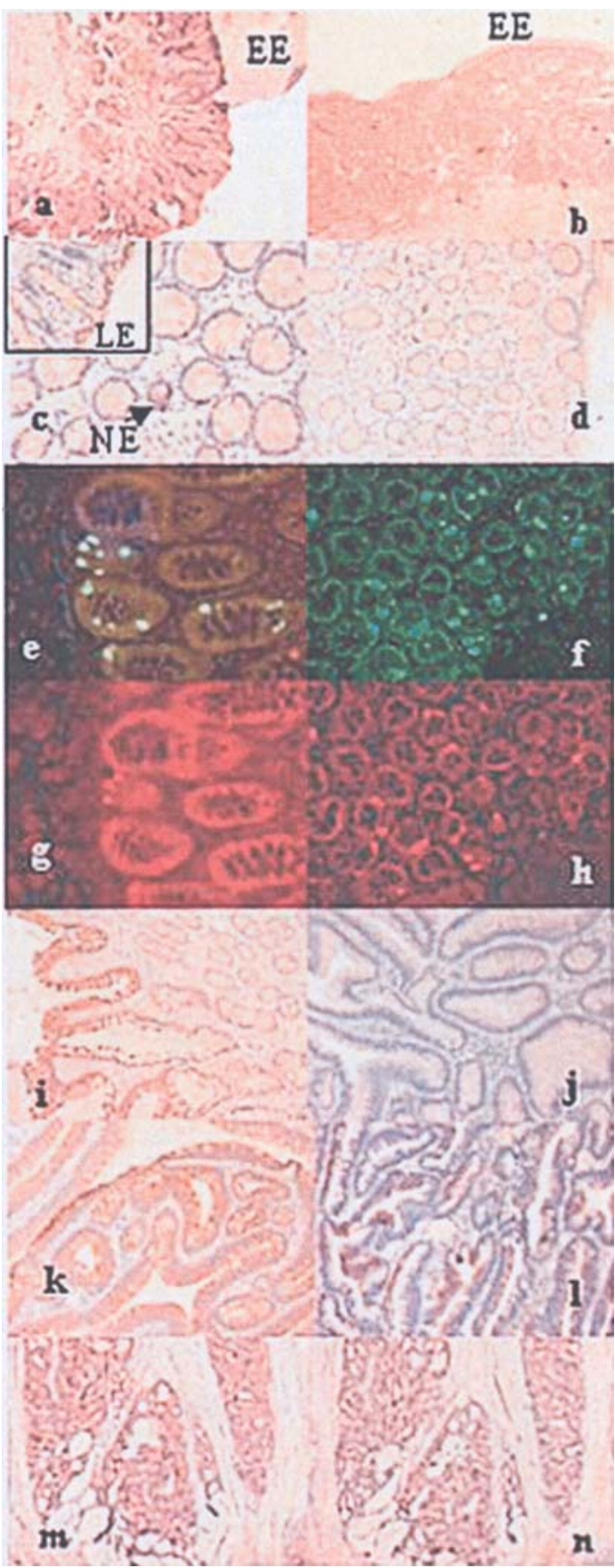

Figure 2. Representative microphotographs of GHRH-R (left column: a, c, $\mathrm{e}, \mathrm{g}, \mathrm{i}, \mathrm{k}$ and $\mathrm{m}$ ) and SV-1 (right column: b, d, f, h, j, 1 and n) immunostaining of Barrett's adenocarcinoma with normal oesophageal mucosa (EE) ( $a$ and b) and normal and transformed human colonic mucosa. In normal mucosa (c and d) only neuroendocrine cells (NE) or lining epithelium (LE) stained weakly positive for GHRH-R, while crypts remained negative. (e, f, g and h) show double staining of NE cells in normal colonic mucosa with antiGHRH-R antibody JH2321/5 (red color) (e and g) and anti-SV-1 antibody $\mathrm{JH} 2317 / 5$ (f and h) (red color) and chromogranin A (green color). Tubular adenomas of the colon are shown in $\mathrm{i}$ and $\mathrm{j}$. Tubulovillous adenomas $(\mathrm{k}$ and 1$)$ as well as adenocarcinomas of the colon ( $m$ and $n$ ) were strongly positive for GHRH-R and SV-1.

carcinomas of the colon (Fig. 2n). Interestingly, while adenocarcinomas of the colon showed strong staining for both types of receptors, liver metastases deriving from colonic adenocarcinomas were negative for both GHRH-R and $\mathrm{SV}-1$ receptor. Normal pancreatic tissue as well as adeno- 
Table I. Protein and mRNA expression of GHRH-R and GHRH-R splice variant SV-1 in human normal and neoplastic tissues of the gastrointestinal tract by immunohistochemistry and RT-PCR.

\begin{tabular}{|c|c|c|c|c|}
\hline \multirow[b]{2}{*}{ Tissue } & \multicolumn{2}{|c|}{ Immunohistochemistry } & \multicolumn{2}{|c|}{ RT-PCR } \\
\hline & GHRH-R & $\mathrm{SV}-1$ & GHRH-R & SV-1 \\
\hline Oesophagus & $0 / 3$ & $0 / 3$ & $0 / 3$ & $0 / 3$ \\
\hline Oesophagus cancer (SCC) & $0 / 3$ neg. & $0 / 3$ neg. & $0 / 3$ & $0 / 3$ \\
\hline Barrett's oesophagus & 3/3 st. & $3 / 3$ st. & $3 / 3$ & $3 / 3$ \\
\hline Barrett's carcinoma & $3 / 3$ st. & $3 / 3$ st. & $3 / 3$ & $3 / 3$ \\
\hline Gastric mucosa & 4/4, st. & $0 / 4$ & $4 / 4$ & $0 / 4$ \\
\hline Gastric cancer (AC) & $5 / 5$, st. & $1 / 5$, mod. & $5 / 5$ & $1 / 5$ \\
\hline Cecum & 2/8 w., NE, LE & 0/8 neg., NE & $8 / 8$ & $3 / 8$ \\
\hline Colon transversum & 4/8 w., NE, LE & 0/8 neg., NE & $8 / 8$ & $4 / 8$ \\
\hline Colon sigmoideum & 6/8 w., NE, LE & 0/8 neg., NE & $8 / 8$ & $3 / 8$ \\
\hline Rectum & 2/3 w., NE, LE & 0/3 neg., NE & $2 / 3$ & $2 / 3$ \\
\hline Tubular adenoma & 4/4 st., LE & 0/4 neg., NE & $4 / 4$ & $3 / 4$ \\
\hline Tubulovillous adenoma & $3 / 3$ st. & $3 / 3$ st. & $3 / 3$ & $3 / 3$ \\
\hline Colon cancer (AC) & 9/9 st. & 9/9 st. & $9 / 9$ & $9 / 9$ \\
\hline Liver metastases (Colon-CA) & 0/3 neg., BD & 0/3 neg. & $0 / 3$ & $0 / 3$ \\
\hline Pancreas & 3/3, st. & $0 / 3$, neg. & $3 / 3$ & $0 / 3$ \\
\hline Pancreatic cancer (AC) & 4/4, st. & $0 / 4$, neg. & $4 / 4$ & $0 / 4$ \\
\hline Insulinoma & $2 / 2, \bmod$ & $2 / 2, \bmod$ & $2 / 2$ & $2 / 2$ \\
\hline Gastrinoma & $2 / 2$, st. & $2 / 2, \mathrm{w}$ & $2 / 2$ & $2 / 2$ \\
\hline GIST & $0 / 2$, neg. & $0 / 2$, neg. & $0 / 2$ & $0 / 2$ \\
\hline Liver (normal) & $0 / 3$, neg. & $0 / 3$, neg. & $0 / 3$ & $0 / 3$ \\
\hline $\mathrm{HCC}$ & $0 / 3$, neg. & $0 / 3$, neg. & $0 / 3$ & $0 / 3$ \\
\hline
\end{tabular}

CA, carcinoma; AC, adenocarcinoma; SCC, squamous cell carcinoma; neg., negative; w., weak; mod., moderate; st., strong staining; NE, neuroendocrine cells; LE, lining epithelium; BD, bile duct; GIST, gastrointestinal stromal tumor; HCC, hepatocellular carcinoma.

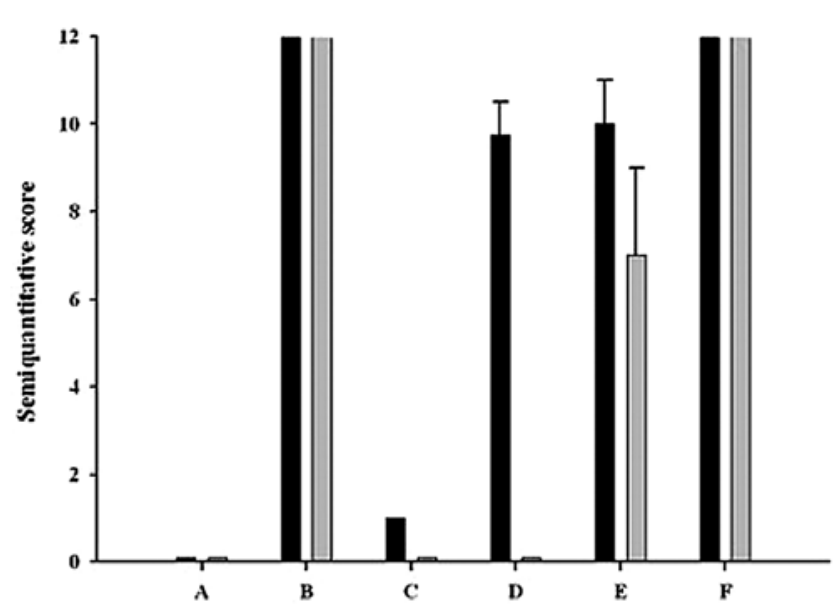

Figure 3. Assessement of labelling of GHRH-R (filled bars) and SV-1 (open bars) immunostaining in normal oesophagus (A), Barrett's adenocarcinoma (B), normal colonic mucosa (C), tubular adenomas (D), tubulovillous adenomas (E) and adenocarcinomas of the colon (F). Semiquantitative scoring was defined by the product of the number of specifically stained tumour cells ( 0 , negative; $1,1-25 \% ; 2,26-50 \% ; 3,51-75 \% ; 4,76-100 \%)$ and the intensity of staining ( 0 , negative; 1 , weak; 2 , moderate; 3 , strong positivity). The product was then graded as 0 , negative; $1-4$, weak; $5-8$, moderate and 9-12, strong staining. carcinomas of the pancreas showed strong staining for GHRH-R, but were negative for SV receptors. Likewise normal pancreatic tissue, neuroendocrine tumours of the pancreas such as insulinomas and gastrinomas were also positive for the GHRH-R receptor and showed weak to modest expression of SV-1 receptor. Gastrointestinal stromal tumours were negative for both receptors. Normal liver tissue and hepatocellular carcinomas did not show the staining for any receptor. The summary of immunohistochemistry is shown in Table I. A graphical representation of the immunochemistry scores in the oesophagus and colon is shown in Fig. 3.

Expression of GHRH-R, SV-1,SV-2 and SV-4 on mRNA level by $R T-P C R$. cDNA of extracted tissue specimens was subjected to RT-PCR and amplicons of interest were subsequently visualized by gel electrophoresis (Fig. 4). Normal human pituitary served as positive control. The results of RTPCR are summarized in Table I. The expression of mRNA for GHRH-R and SV-1 corresponded well to the histological staining, except for some tissues of normal colonic mucosa and tubular adenomas. In some of these samples, mRNA for GHRH-R and SV-1 could not be detected while immuno- 


\section{GHRH-R SV-1 SV-2}

\section{M $12344567712345567 \quad 1234567$ M}

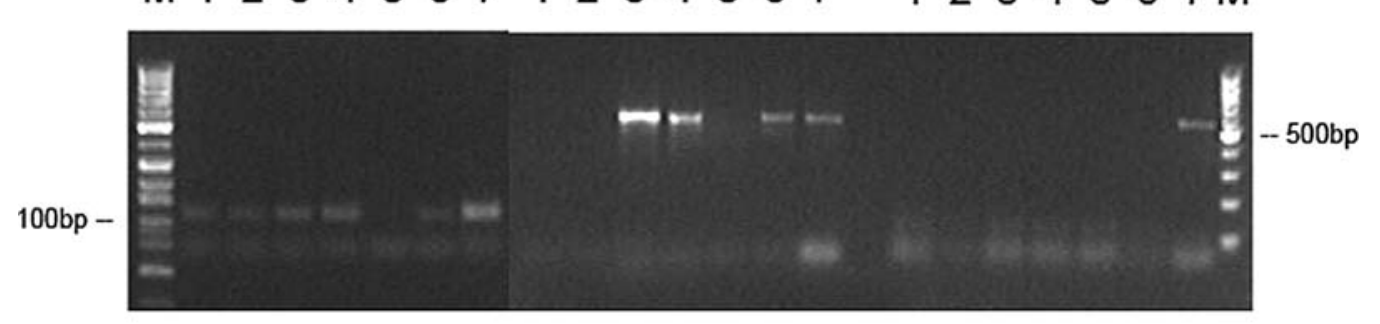

SV-4

GAPDH
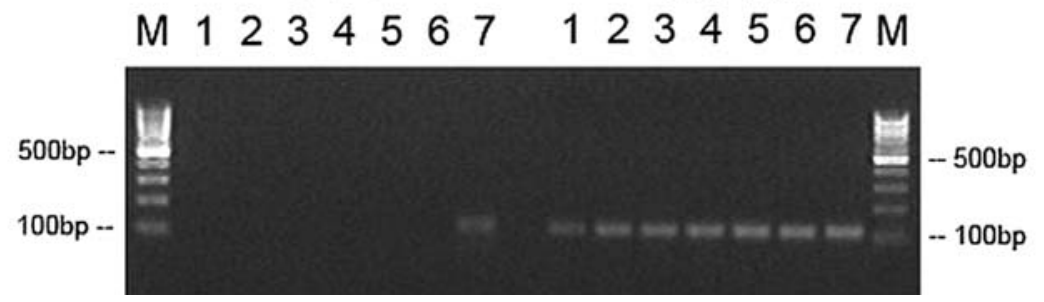

Figure 4. RT-PCR analysis of GHRH-R, SV-1, SV-2, SV-4 and GAPDH in representative samples of human colonic mucosa (1), tubular adenoma (2), tubulovillous adenoma (3), colon cancer (4), oesophageal squamous cell epithelium (5), Barrett's adenocarcinoma (6) and normal human pituitary (7). Products were of the expected size of $145,523,526$ and 120 bp corresponding to GHRH-R, SV-1, SV-2 and SV-4, respectively. DNA molecular weight marker is presented in lane $\mathrm{M}$.

histochemistry clearly identified neuroendocrine cells or lining epithelium as the source for GHRH-R and SV-1 positivity in these samples. mRNA of SV-2 and SV-4 could not be detected in any of the samples tested other than normal human pituitary (data not shown).

\section{Discussion}

Independently of its neuroendocrine action, GHRH is now recognized as an autocrine/paracrine growth factor for various human cancers, including experimental gastric, colonic and pancreatic cancers $(1,2)$. In spite of the demonstrated ability of GHRH to promote cancer growth, the mechanisms that mediate its mitogenic effects remain poorly characterized, particularly at the level of the receptors(s) (12-14).

Recently, our group ascertained that GHRH-R is also present in extrapituitary tissues such as human non-small cell lung carcinoma (NSCLC), cancer cell lines including MiaPaCa-2 pancreatic cancer cell line, and normal human tissues (5). Pombo et al demonstrated that GHRH leads to an activation of MAPK in Chinese hamster ovarian cells overexpressing the human GHRH-R (15). Furthermore, it has been shown in MCF-7 human breast cancer cell lines, transfected with GHRH-R, that the full receptor can be operative in extrapituitary tissues (7). However, the main action of GHRH is thought to be mediated by SV-1 receptor which is widely expressed in different human primary and experimental cancers and which can elicit mitogenic responses in the presence of GHRH (9). In addition to its GHRH-dependent activity, SV-1 exerts also some ligand independent activity $(7,8)$.

In this study, we analyzed the expression of GHRH-R and SV-1, 2 and 4 in normal and neoplastic tissues of the GI-tract by immunohistochemistry and RT-PCR. Quantification of mRNA expression by means of real-time PCR revealed very low mRNA levels for GHRH-R and SV-1 (data not shown). Thus, a quantitative approach was not considered useful because of disproportionally large errors of such calculations. However, assessment of mRNA for GHRH-R and SV-1 showed a near-perfect correlation with the presence of receptor proteins assessed by immunohistochemical staining (Table I). For immunohistochemistry testing we used antibodies raised against the N-terminus of segment 1-25 of the SV-1 receptor protein, which is also shared by SV-2 and SV-4 and thus is detectable by the anti-SV-1 antibody (10). However, since we did not detect any mRNA for SV-2 or SV-4 in the samples tested, we can exclude a potential presence of SV-2 and SV-4 in these samples. The specificity of antibody for SVs has been documented in a number of previous studies using various methods, including the immunostaining of cells transfected with SV-1 $(7,9)$ or abolishing of immunostaining after silencing of SV-1 expression (8). Other studies by Western blotting showed the presence of specific bands for SV-1 $(5,6,10)$. In our study, we found that tissues which do not express mRNA for SV-1 showed no immunostaining, which is a further proof that the antibody does not recognize other proteins unrelated to SV-1. The specificity of the antibody for GHRH-R was previously demonstrated by Western blotting $(5,6,10)$. In the present study, as in the case of SV-1 antibody, tissues that did not express mRNA for GHRH-R, showed negative immunostaining for GHRH-R antibody. In addition, we demonstrated that the immunopositivity was abolished by pre-incubating the antiserum with increasing concentrations of the corresponding original peptide used for the immunization of rabbits as described in Materials and methods (10). While we could not observe any differences in the expression pattern of GHRH-R and SV-1 in normal and neoplastic tissue of the stomach, pancreas and liver, we detected a distinct distribution of both receptors in normal and neoplastic tissues of 
the oesophagus and the colon (Table I, Figs. 2, 3 and 4). Thus, we could demonstrate that the malignant transformation from normal to metaplastic Barrett's mucosa and adenocarcinomas of the oesophagus was correlated with a strong expression of GHRH-R, as well as SV-1 receptor, whereas normal oesophageal squamous cells and squamous cell carcinoma of the oesophagus were negative for both receptors. Barrett's oesophagus is defined as the replacement (metaplasia) of the normal oesophageal squamous cells with columnar epithelium containing goblet cells. This abnormal specialized columnar epithelium predisposes patients to the development of mucosal dysplasia and ultimately adenocarcinoma. Cyclin D1 is a key regulator of cell cycle progression, particularly at the transition from G1 to the $S$ phase. It has been shown previously that cyclin D1 plays a key role in oesophageal malignancy, and an overexpression of cyclin D1 protein has been reported in up to $64 \%$ of adenocarcinomas and associated Barrett's epithelia $(16,17)$. A phase III casecontrol study showed that immunohistochemical overexpression of cyclin D1 in patients with Barrett's oesophagus was associated with an increased risk for progression to oeso-phageal adenocarcinoma (17). Cyclin D1 is elevated in cells expressing GHRH-R and SV-1 after exposure to GHRH (7). GHRH-R and conceivably SV-1 receptor share the intracellular part and operate by mechanisms that involve the activation of Ras signalling $(15,18)$. Cyclin D1 is a well established target of activation of Ras signalling, which has been shown to be down-regulated by antagonists of GHRH in experimental lung carcinomas (6).

Colorectal carcinogenesis occurs as a multi-step process that requires sequential or concomitant damage to several genes within and across cellular generations. The development of colorectal cancer is characterized by a well defined sequence of events from abberant crypt proliferation or hyperplasia to benign adenomas, then to carcinoma in situ and finally metastatic carcinoma (19). In our study, we could show, that the expression of GHRH-R increases significantly in this adenoma-carcinoma sequence, being most prominent in colorectal cancers (Table I, Figs. $2 \mathrm{~h}$ and 3 ). While the expression of SV-1 receptor was completely absent in normal colon mucosa and in tubular adenomas, except for neuroendocrine cells, SV-1 receptor staining could be demonstrated in tubulovillous adenomas and also in carcinomas. These findings imply a role for GHRH-R and SV-1 in colorectal carcinogenesis. The transfection of SV-1 stimulated growth of MCF-7 human breast cancer cells in semisolid medium, an assay considered diagnostic for cell transformation (7).

Colorectal cancer develops through a multi-step process including activation of oncogenes such as K-Ras, alterations of tumour suppressor genes such as p53, overexpression of molecules and growth factors such as Cox-2 and insulin-like growth factor II (IGF-II) (20). We previously showed, that inhibition of experimental lung adenocarcinomas by antagonistic analogues of GHRH was associated with downregulation of K-Ras, Cox-2 and mutated p53 (6,21). Furthermore, the antiproliferative effect of GHRH-antagonists against experimental human colon cancer could be linked with a suppression of tumoural IGF-II production (22).

Interestingly, in contrast to the detection of GHRH-R and SV-1 in colorectal carcinomas, metastases of colorectal cancers did not show the presence of any receptor. Despite a possible bias due to the small number of samples tested in this study, our results are in accordance with a previously published immunohistochemical analysis of gastrin releasing peptide (GRP) and its receptor (GRP-R) in colon cancers and metastases of colorectal cancers (23). Thus, it has been shown that only 2 out of 37 metastases were positive for GRP-R. The association of GRP/GRP-R to better differentiated cells raised the possibility that GRP could act primarily as a morphogen (23).

The physiological and pathophysiological significance of the expression and co-expression of the GHRHRs in normal and tumoural tissues still has to be elucidated. Recent identification of another SV of GHRH-R that differs from the full-length receptor at the $3^{\prime}$ end (3-end SV) and operates as a dominant-negative form of the receptor, imply that alternative SVs of the GHRH-R may form a complex regulatory network (24). Thus, it is conceivable that GHRH-R activity is determined not only by the abundance of the GHRH, but also by the relative levels of these SVs that produce either positive (SV-1) or negative (3-end SV) effects of GHRH-R signalling.

Taken together, our study shows that in contrast to normal mucosa, transformed mucosa of the oesophagus and the colon expresses GHRH-R and SV-1. An expression of GHRH-R and SV-1 in oesophageal and colorectal malignancies may provide a molecular target for a therapeutic approach based on GHRH antagonists.

\section{Acknowledgements}

We acknowledge the financial support of Private Medical University of Salzburg (Salzburg, Austria) (F.H). Foundation Propter Homines, Fürstentum Liechtenstein, Vaduz, (C.D). Medical Research Service of the Veterans Affairs and South Florida Veterans Affairs Foundation for Research and Education through a Grant from Zentaris AG, Frankfurt am Main Germany, and Department of Pathology, and Sylvester Comprehensive Cancer Center of the Miller Medical School, University of Miami (A.V.S, J.L.V. and M.Z.)

\section{References}

1. Schally AV, Comaru-Schally AM, Nagy A, et al: Hypothalamic hormones and cancer. Front Neuroendocrinol 22: 248-291, 2001.

2. Busto R, Schally AV, Varga JL, et al: The expression of growth hormone-releasing hormone $(\mathrm{GHRH})$ and splice variants of its receptor in human gastroenteropancreatic carcinomas. Proc Natl Acad Sci USA 99: 11866-11871, 2002.

3. Halmos G, Schally AV, Czompoly T, Krupa M, Varga JL and Rekasi Z: Expression of growth hormone-releasing hormone and its receptor splice variants in human prostate cancer. J Clin Endocrinol Metab 87: 4707-4714, 2002.

4. Halmos G, Schally AV, Varga JL, Plonowski A, Rekasi Z and Czompoly T: Human renal cell carcinoma expresses distinct binding sites for growth hormone-releasing hormone. Proc Natl Acad Sci USA 97: 10555-10560, 2000.

5. Havt A, Schally AV, Halmos G, et al: The expression of the pituitary growth hormone-releasing hormone receptor and its splice variants in normal and neoplastic human tissues. Proc Natl Acad Sci USA 102: 17424-17429, 2005.

6. Hohla F, Schally AV, Szepeshazi K, et al: Synergistic inhibition of growth of lung carcinomas by antagonists of growth hormonereleasing hormone in combination with docetaxel. Proc Natl Acad Sci USA 103: 14513-14518, 2006 
7. Barabutis N, Tsellou E, Schally AV, Kouloheri S, Kalofoutis A and Kiaris H: Stimulation of proliferation of MCF-7 breast cancer cells by a transfected splice variant of growth hormone-releasing hormone receptor. Proc Natl Acad Sci USA 104: 5575-5579, 2007.

8. Kiaris H, Chatzistamou I, Schally AV, et al: Ligand-dependent and -independent effects of splice variant 1 of growth hormonereleasing hormone receptor. Proc Natl Acad Sci USA 100: 9512-9517, 2003

9. Kiaris H, Schally AV, Busto R, Halmos G, Artavanis-Tsakonas S and Varga JL: Expression of a splice variant of the receptor for GHRH in 3T3 fibroblasts activates cell proliferation responses to GHRH analogs. Proc Natl Acad Sci USA 99: 196-200, 2002.

10. Toller GL, Horvath JE, Schally AV, et al: Development of a polyclonal antiserum for the detection of the isoforms of the receptors for human growth hormone-releasing hormone on tumours. Proc Natl Acad Sci USA 101: 15160-15165, 2004.

11. Chomczynski P and Sacchi N: Single-step method of RNA isolation by acid guanidinium thiocyanate-phenol-chloroform extraction. Anal Biochem 162: 156-159, 1987.

12. Kiaris H, Koutsilieris M, Kalofoutis A and Schally AV: Growth hormone-releasing hormone and extra-pituitary tumourigenesis: therapeutic and diagnostic applications of growth hormonereleasing hormone antagonists. Expert Opin Investig Drugs 12: 1385-1394, 2003.

13. Kiaris H, Schally AV and Kalofoutis A: Extrapituitary effects of the growth hormone-releasing hormone. Vitam Horm 70: 1-24, 2005.

14. Schally AV and Varga JL: Antagonists of growth hormonereleasing hormone in oncology. Comb Chem High Throughput Screen 9: 163-170, 2006.

15. Pombo CM, Zalvide J, Gaylinn BD and Dieguez C: Growth hormone-releasing hormone stimulates mitogen-activated protein kinase. Endocrinology 141: 2113-2119, 2000.
16. Arber N, Lightdale C, Rotterdam H, et al: Increased expression of the cyclin D1 gene in Barrett's oesophagus. Cancer Epidemiol Biomarkers Prev 5: 457-459, 1996.

17. Bani-Hani K, Martin IG, Hardie LJ, et al: Prospective study of cyclin D1 overexpression in Barrett's oesophagus: association with increased risk of adenocarcinoma. J Natl Cancer Inst 92: 1316-1321, 2000

18. Siriwardana G, Bradford A, Coy D and Zeitler P: Autocrine/ paracrine regulation of breast cancer cell proliferation by growth hormone releasing hormone via Ras, Raf, and mitogen-activated protein kinase. Mol Endocrinol 20: 2010-2019, 2006.

19. Morson B: President's address. The polyp-cancer sequence in the large bowel. Proc R Soc Med 67: 451-457, 1974.

20. Chung DC: The genetic basis of colorectal cancer: insights 854-865, 2000.

21. Kanashiro CA, Schally AV, Groot K, Armatis P, Bernardino AL and Varga JL: Inhibition of mutant p53 expression and growth of DMS-153 small cell lung carcinoma by antagonists of growth hormone-releasing hormone and bombesin. Proc Natl Acad Sci USA 100: 15836-15841, 2003.

22. Szepeshazi K, Schally AV, Groot K, et al: Antagonists of growth hormone-releasing hormone (GH-RH) inhibit IGF-II production and growth of HT-29 human colon cancers. Br J Cancer 82: 1724-1731, 2000.

23. Carroll RE, Matkowskyj KA, Chakrabarti S, McDonald TJ and Benya RV: Aberrant expression of gastrin-releasing peptide and its receptor by well-differentiated colon cancers in humans. Am J Physiol 276: G655-G665, 1999.

24. McElvaine AT and Mayo KE: A dominant-negative human growth hormone-releasing hormone $(\mathrm{GHRH})$ receptor splice variant inhibits GHRH binding. Endocrinology 147: 1884-1894, 2006. 